\title{
Sôbre uma propriedade da equação utilizada para interpolação da Lei de Mitscherlich
}

IZAIAS RANGEL NOGUEIRA

Assistente Substituto de Matemática da E. S. A. "Luiz de Queiroz"

O método dos quadrados mínimos, aplicada à equação de Mitscherlich

$$
\begin{aligned}
& y=A\left[1-10^{-c(x+b)}\right] \text {, conduz ao determinante }
\end{aligned}
$$

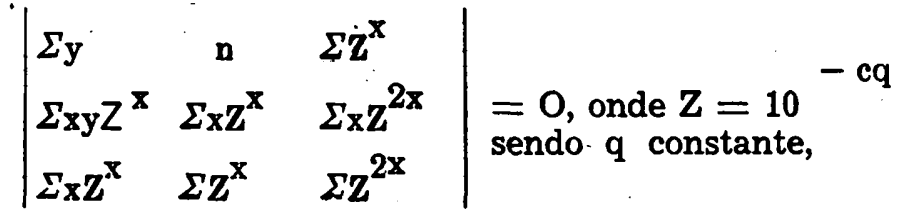

como mostraram Pimentel Gomes e Malavolta (1949)

Nota-se à primeira vista a exsitência de uma raiz $\mathrm{Z}=1$ para aquela equação.

Nogueira (1950), salientou essa propriedade da equação (1). Após aquêle trabalho, verificou que a raiz $Z=1$ é tripla.

Este fato foi notado em todos os casos pesquisados, o que nos levou a procurar prová-lo de um modo geral.

Derivando-se em relação a $Z$, o determinante acima e tomando-se $\mathrm{Z}=1$, encontra-se : 


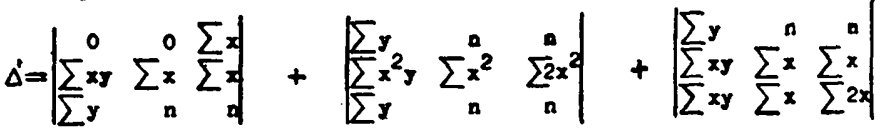

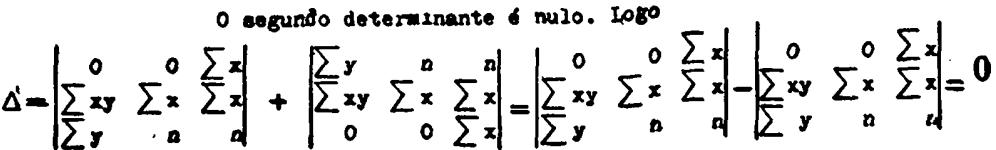

$$
\begin{aligned}
& \text { Derivando outre ves o tomando } z=3 \text {, tewos }
\end{aligned}
$$

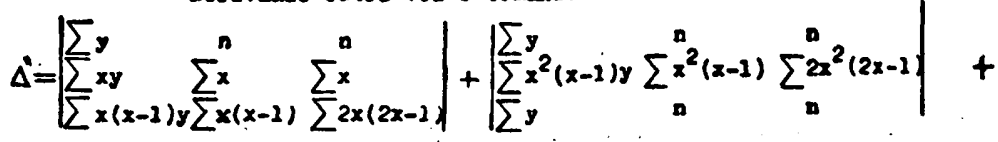

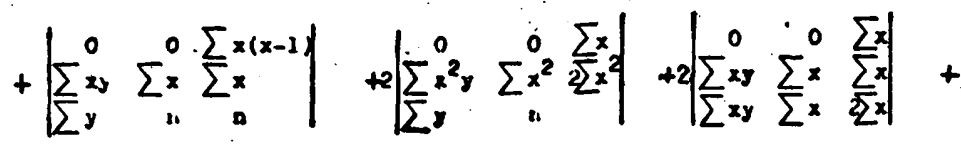

$$
\begin{aligned}
& +2\left|\begin{array}{lll}
\sum y & n \\
\sum x^{2} y & \sum x^{2} & \sum^{n} x^{2} \\
\sum x y & \sum x & \frac{2}{2 x}
\end{array}\right|
\end{aligned}
$$

0. determinantes $22 \cdot 59$ eridentosente sto miss. Logo temos:

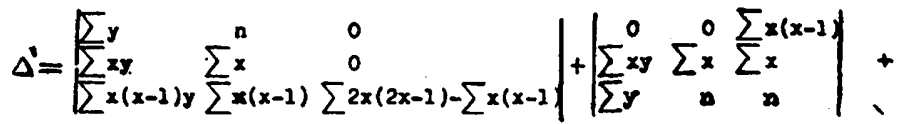

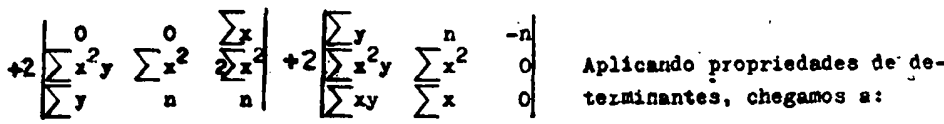

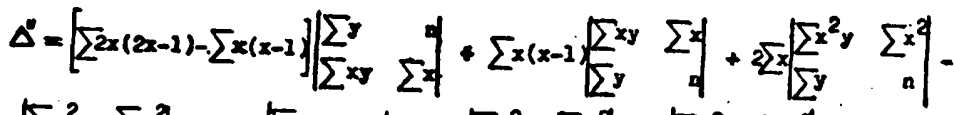

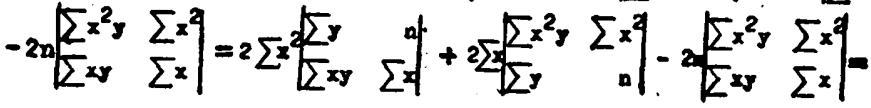

$$
=\left|\begin{array}{lll}
2 \sum x^{2} & \sum x^{2} y & \sum x^{2} \\
2 n & \sum y & n \\
2 \sum x & \sum x y & \sum x
\end{array}\right|=0
$$

Portanto, fica provada a existência daquela raiz tripla para qualquer caso.

Encontramos exemplos em que a derivada terceira não se anulou. Logo a existência de raiz igual a 1 com ordem de multiplicidade superior a três não se dá necessàriamente. 
Este fato favorece muito a resolução da equação resultante do desenvolvimento do determinante, que, em geral, é de grau elevado, pelos seguintes motivos:

1) Se a equação obtida não for divisível por $(Z-1) 3$, ela está errada.

2) Uma vez eliminada a raiz múltipla, resulta uma equação de grau inferior ao anterior (grau $n-3$ ), donde favorecer o cálculo da raiz compreendida entre 0 e 1 , que é a única que nos interessa.

3) Se a equação resultante da eliminação daquela raiz múltipla, só tiver permanências de sinal, isso indica, como sabemos da Algebra elementar, a existência sòmente de raízes negativas. Como o valor de $\mathbf{Z}$ que interessa é positivo, não precisamos continuar o cálculo, pois aquela raiz não existe.

4) A existência dessa raiz tripla veio facilitar a tabulação dos polinômios necessários à resolução da equação (1) por meio de tabelas conforme trabalho em preparo.

Como exemplo, apresentamos um trabalho por nós pesquisado, em um dos dados que nos foram gentilmente fornecidos pelo Dr. Glauco Pinto Viegas; do Instituto Agronômico de Campinas.

No ano de 43-44 em Taíuva fizeram ùma adubação fosfatada nas doses de 40,80 e $120 \mathrm{~kg} / \mathrm{ha}$, além da testemunha.

Se tomarmos como unidade, para facilitar o cálculo, 40 $\mathrm{kg} / \mathrm{ha}$, as doses serão $0,1,2$ e 3 .

Em resumo:

\begin{tabular}{c|c|c}
\hline & $\begin{array}{c}\text { Colheita obtida, } \\
\text { soma de 6 } \\
\text { repetigóes }\end{array}$ & Médias \\
\hline 0 & 19,76 & 3,293 \\
1 & 26,45 & 4,408 \\
2 & $\therefore 28,49$ & 4,748 \\
3 & 28,62 & 4,770 \\
\hline
\end{tabular}

Soma total

17,219

Aplicando a equação (1), chegamos à equação do 7.0 grau : $10,77 \mathrm{Z7}-1,73 \mathrm{Z6}-39,75 \mathrm{Z5}+30,71 \mathrm{Z4}-2,09 \mathrm{Z} 3+$ $+19,29 \mathrm{Z}^{2}-21,41 \mathrm{z}+4,21=0$

Dividindo por $(\mathrm{Z}-1)^{3}$, temos : 
(2) $10,77 \mathrm{Z}^{4}+30,58 \mathrm{Z}^{3}+19,68 \mathrm{Z}^{2}+8,78 \mathrm{Z}+4,21=0$, cujo valor de $Z$ determinado pelo processo de aproximação da Algebra Elementar é $Z=0,2604$.

Com êsse valor fàcilmente determinamos os parâmetros c, b e A, da equação de. Mitscherlich.

A equação obtida é : $y=4,833\left[1-10^{-0,584359}(x+0,8357)\right]$

Note-se que a equação (2) demonstra à primeira vista a existência de uma raiz positiva, pois tem uma variação.

\section{BIBLIOGRAFIA CITADA}

PIMENTEL GOMES, Frederico e Euripedes MALAVOLTA Considerações Matemáticas sôbre a Lei de Mitscherlich. Piracicaba, 1949.

NOGUEIRA, Izaias Rangel - A Técnica da resolução das equações Relativas à Interpolação da lei de Mitscherlich, pelo Método dos Quadrados Mínimos.

\section{ABSTRACT}

The author proves that equation,

$$
\left|\begin{array}{lcl}
\Sigma \mathrm{y} & \mathrm{n} & \Sigma \mathrm{z}^{\mathrm{x}} \\
\Sigma \mathrm{xy} \mathrm{Z}^{\mathrm{x}} & \Sigma \mathrm{x} \mathrm{Z}^{\mathrm{x}} & \Sigma \mathrm{xz}^{2 \mathrm{x}} \\
\Sigma \mathrm{y} & \Sigma \mathrm{z}^{\mathrm{x}} & \Sigma \mathrm{z}^{2 \mathrm{x}}
\end{array}\right|=0
$$

where $\mathrm{Z}=10^{-\mathrm{cq}}$ and $\mathrm{q}$ is a numerical constant, used by Pimentel Gomes and Malavolta in several articles for the interpolation of Mitscherlih's equation

$$
y=A[1-10-(x+b)]
$$

by the least squares method, always has a zero of order three for $\mathrm{Z}=1$. Therefore, equation

$$
\mathrm{A} \mathrm{Z}^{\mathrm{m}}+\mathrm{A}_{1} \mathrm{Z}^{\mathrm{m}-1}+\cdots \ldots \ldots \ldots+\mathrm{A}_{\mathrm{m}}=0
$$

obtained from that determinant can be divided by $(Z-1) 3$.

This property .provides a good test for the correctness of the computaticns and facilitates the solution of the equation. 